\title{
Crystal engineering of ultramicroporous materials
}

\author{
M. Zaworotko \\ Bernal Institute and School of Chemical Sciences, University of Limerick, Limerick, Ireland \\ xtal@ul.ie
}

That composition and structure profoundly impact the properties of crystalline solids has provided impetus for exponential growth in the field of crystal engineering over the past 25 years. Crystal engineering has evolved from structure design (form) to control over bulk properties (function). Today, when coupled with molecular modeling, crystal engineering can offer a paradigm shift from the more random, high-throughput methods that have traditionally been utilized in materials discovery and development. Custom-design of the right crystalline material for the right application could therefore be at hand.

Porous crystalline materials exemplify this situation. Whereas purely inorganic materials (e.g. zeolites) and those based upon coordination chemistry (e.g. Metal-Organic Frameworks, MOFs, and Porous Coordination Polymers, PCPs) are well studied and offer great promise for separations and catalysis, they are often handicapped by cost or performance (e.g. poor chemical stability, interference from water vapour, low selectivity) limitations. Ultramicroporous Materials, UMs, are built from metal or metal cluster "nodes" and combinations of organic and inorganic "linkers" and their pore chemistry and size $(<0.7 \mathrm{~nm})$ can overcome some of the weaknesses of existing classes of porous material (Figure 1). Three families (platforms) of UMs will be detailed and their performance with respect to important gas separation (e.g. $\mathrm{CO}_{2}$ capture [1], $\mathrm{C}_{2} \mathrm{H}_{2}$ capture [2]) and water purification applications will be discussed. Most recently, we have shown that UMs can function synergistically to address complex gas mixtures [3] or perform effectively for $\mathrm{CO}_{2}$ capture even in the presence of humidity [4].
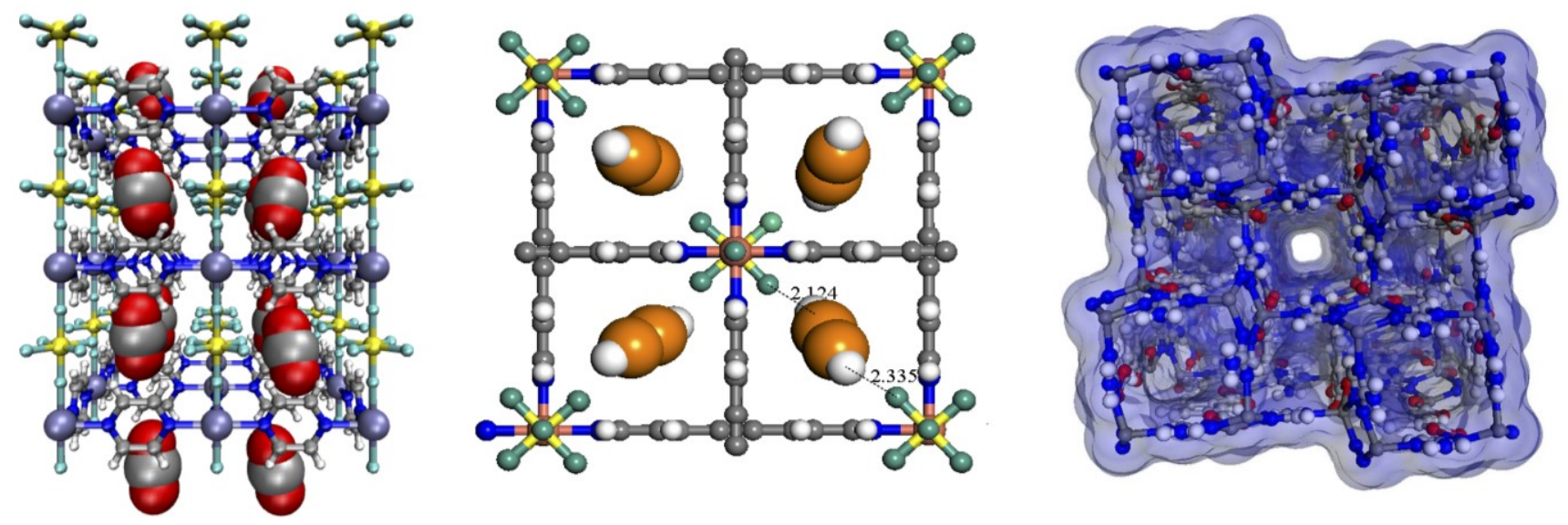

Figure 1. Ultramicroporous materials offer benchmark selectivity for $\mathrm{CO}_{2}$ (left), $\mathrm{C}_{2} \mathrm{H}_{2}$ (middle) and $\mathrm{C}_{2} \mathrm{H}_{6}$ (right).

[1] Nugent, P. Nugent, P.; Belmabkhout, Y.; Burd, S.D.; Cairns, A.J.; Luebke, R.; Forrest, K.; Pham, T.; Ma, S.; Space, B.; Wojtas, L.; Edda oudi, M.; Zaworotko, M.J. (2013) Nature 495, 80-84.

[2] Cui, X.; Chen, K.J.; Xing, H.; Yang, Q.; Krishna, R.; Bao, Z.; Wu, H.; Zhou, W.; Dong, X.; Li, B.; Ren, Q.; Zaworotko, M.J.; Chen, B. (2016). Science 353, 141-144.

[3] Chen, K.J.; Madden, D.G.; Mukherjee, S.; Pham, T.; Forrest, K.A.; Kumar, A.; Space, B.; Kong, J.; Zhang, Q.Y. Zaworotko, M.J. (2019). Science, 366, 241-246.

[4] Mukherjee, S.; Sikdar, N.; O’Nolan, D.; Franz, D.M.; Gascon, V.; Kumar, A.; Kumar, N.; Scott, H.S.; Madden, D.G.; Kruger, P.E.; Space, B.; Zaworotko, M.J. (2019). Science Adv. 5, eaax9171.

\section{Keywords: Sorbent; ultramicropore; carbon capture, ethylene purification; water harvesting}

Any acknowledgements authors wish to make should be included at the end of the manuscript with no heading (use Acknowledgement style, Times New Roman 10 pt, italics). 